\title{
Constitutive Modeling for Al-Cu-Mg Alloy in Creep Aging Process
}

\author{
Y. L. Yang, ${ }^{\text {a,b,c }}$ L. H. Zhan, ${ }^{\mathrm{a}, \mathrm{b}, \mathrm{c}, 1}$ and X. L. Xu, ${ }^{\mathrm{a}, \mathrm{b}, \mathrm{c}}$ \\ a State Key Laboratory of High-Performance Complex Manufacturing, Central South University, \\ Changsha, China \\ b School of Mechanical and Electrical Engineering, Central South University, Changsha, China \\ ${ }^{c}$ Collaborative Innovation Center of Advanced Nonferrous Materials and Manufacturing, Central \\ South University, Changsha, China \\ ${ }^{1}$ yjs-cast@csu.edu.cn
}

The aim of this paper is to develop a set of creep aging constitutive equations for $\mathrm{Al}-\mathrm{Cu}-\mathrm{Mg}$ alloys containing plate- or rod-like precipitates. Average length, aspect ratio and relative volume fraction are introduced to quantitatively analyze precipitates evaluation of such alloy in creep aging process. The strong interaction between creep deformation and aging treatment is considered by the intermediate state variables of dislocation density and precipitate characteristic dimension. A unified creep aging constitutive equation is derived, in which the correlations between microscopic characteristics and macroperformances of material are linked by the yield strength of the material. Using AA2124 as subject, a series of uniaxial tensile creep tests are carried out at $185^{\circ} \mathrm{C}$ for $12 \mathrm{~h}$ under different stresses. The material constants within constitutive models are determined with the experimental data. A good agreement between experimental and computed values confirms that the established constitutive equations can well characterize the creep behaviors.

Keywords: constitutive modeling, $\mathrm{Al}-\mathrm{Cu}-\mathrm{Mg}$ alloy, creep aging, microstructure evolution.

Introduction. With increasing market demands for cost reduction and good comprehensive performances, aluminum alloys are extensively used in the industries [1-3]. For example, truss structures constructed of AA6061-OA/T6 (Al-Mg-Si alloys) are equipped with good dynamic crush resistance and energy absorbing capability when undergoing uniaxial impact loading [4-7]; automobile parts made of aluminum alloy can make automobile lightweight and accomplish energy-saving and emission reduction [8]. $\mathrm{Al}-\mathrm{Cu}-\mathrm{Mg}$ alloys are typical deformable and hardenable alloys. They are intensively adopted to manufacture large aircraft integral panels or structures due to high strength to weight ratio, lightweight and high resistance to corrosion with proper heat treatment [9-11]. However, how to accurately deform aluminum alloy to obtain large integral component with desired configuration and properties is an extremely difficult problem. Either high residual stress exists in formed part or final mechanical properties of the part are not satisfied. Therefore creep age forming (CAF), a combined process of creep forming and aging treatment, is a favored forming process and becomes a research focus.

In CAF process, component to be formed remains in full contact with tool surface by pressure at a certain temperature in the autoclave. After a given time, the component is shaped due to creep deformation and the material's properties are enhanced owing to artificial aging. The deformation history and ultimate mechanical properties of the formed component can be predicted by creep aging constitutive equations of the alloy. So establishing constitutive equations of material is indispensable and significant.

With the objective of investigating constitutive models, lots of efforts have been made over last twenty years. Sallah et al. [12] proposed a simplified inelastic constitutive equation for autoclave age forming using a cylindrical tool shape and a good agreement was obtained between the predictions and Textron data. Kowalewski et al. [13] developed a unified mechanisms-based constitutive equation with three internal state variables, which 
can model the primary, secondary, and tertiary creep. In recent years, more and more attention has been paid to microstructure evolution because the size, volume fraction, morphology and distribution of precipitates exert key influence on mechanical properties and marc-creep behaviors of aluminum alloy. Ho et al. [14] constructed a set of physically based unified aging-creep constitutive equations for AA7010. Zhan et al. [15] established a creep aging constitutive models for AA7055 which takes the normalized radius, and normalized dislocation density into account. The investigated precipitates in their works are the spherical shape. For plate-shaped precipitates, Li et al. [16] studied the mean radius and volume percentage of precipitates and correspondingly derived the constitutive equations for AA7B04. Zhang et al. [17] preliminarily explored the microstructure variation in terms of dislocation density, the size, volume fraction and aspect ratio of precipitates and hence proposed a constitutive equation set. However, although the precipitate variation has been studied by various characteristic parameters, the interaction between them and their effects on creep deformation and age hardening have not fully or properly formulated. Further efforts are required to develop mechanism-based creep aging constitutive equations for aluminum alloys where the correlations between precipitate evolution, creep deformation and aging hardening are coupled adequately.

The aim of this paper is to develop a set of creep aging constitutive equations for $\mathrm{Al}-\mathrm{Cu}-\mathrm{Mg}$ alloys. The main strengthening precipitates of $\mathrm{Al}-\mathrm{Cu}-\mathrm{Mg}$ alloys in aging process are $S^{\prime}$ phases $\left(\mathrm{Al}_{2} \mathrm{CuMg}\right)$ or $\theta^{\prime}$ phases $\left(\mathrm{Al}_{2} \mathrm{Cu}\right)$. They are either plate or rod shape. In first part, using AA2124 as material (one of $\mathrm{Al}-\mathrm{Cu}-\mathrm{Mg}$ alloys), a series of uniaxial constant-stress creep tests are carried out at the temperature of $185^{\circ} \mathrm{C}$ under the stresses of 200, 225, and $250 \mathrm{MPa}$ for $12 \mathrm{~h}$. In the second part, the average length $L$, aspect ratio $q$, and relative volume fraction $\bar{f}_{v}$ are introduced to quantitatively determine the evolution of precipitates. In the third part, a unified mechanisms-based creep aging constitutive equation set is established for $\mathrm{Al}-\mathrm{Cu}-\mathrm{Mg}$ alloys under isothermal aging condition. In last part, with the data from experimental tests, material constants in constitutive equation set are determined for AA2124 and then predicted values calculated through models are compared with experimental data.

\section{Experimental Methods.}

1.1. Test Materials. The studied material is a commercial AA2124-T851, which was supplied by Southwest Aluminum Co. Ltd. The normal chemical composition of AA2124-T851 is $4.67 \% \mathrm{Cu}, 1.46 \% \mathrm{Mg}, 0.63 \% \mathrm{Mn}, 0.18 \% \mathrm{Fe}, 0.12 \% \mathrm{Si}, 0.04 \% \mathrm{Zn}, 0.01 \%$ $\mathrm{Ti}, 0.01 \% \mathrm{Ni}$, (bal.) Al. Creep specimens were machined out in the rolling direction from the 2124-T851 plate as shown in Fig. 1. After solution treatment $\left(490^{\circ} \mathrm{C} / 50 \mathrm{~min}\right)$, the specimens were immediately subjected to water quenching. Subsequently the specimens were kept in the refrigerator $\left(-18^{\circ} \mathrm{C}\right)$ to reduce natural aging. Prior to tests, all specimens should be polished by abrasive papers of $\# 400$ and $\# 600$ to eliminate surface defects.

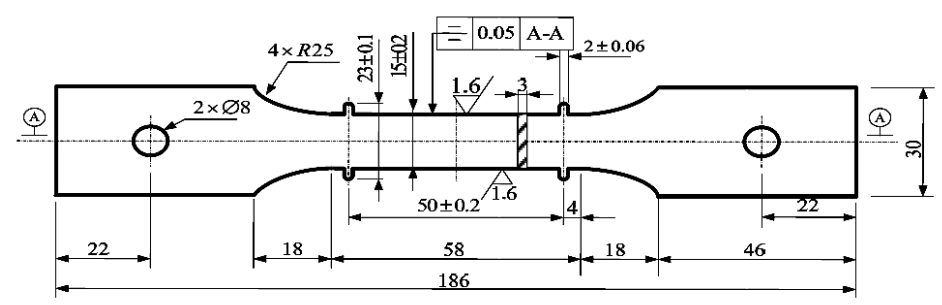

Fig. 1. Geometry of high-temperature creep specimen (unit: $\mathrm{mm}$ ).

1.2. Test Procedures. Uniaxial constant-stress tensile creep tests were carried out on specimens at $185^{\circ} \mathrm{C}$ for $12 \mathrm{~h}$ under different stresses. The yield strength of the tested alloy at $185^{\circ} \mathrm{C}$ was determined to be $225 \mathrm{MPa}$. To examine the creep deformation behaviors of 
the material within and beyond the elastic range, the applied stresses were selected for 200, 225 , and $250 \mathrm{MPa}$. Creep tests under each condition were not less than three times to precisely describe the creep behaviors of the material. Room temperature tensile tests were conducted on creep-aged specimens with a universal testing machine to obtain yield strength. Microstructure observations were performed with a JEOL-2010 transmission electron microscope operating at $200 \mathrm{kV}$. TEM samples were first machined down to $80 \mu \mathrm{m}$ in thickness, followed by standard twin-jet electropolishing using 70\% methanol and 30\% nitric acid solution at -35 to $-25^{\circ} \mathrm{C}$ cooled by liquid nitrogen and lastly by anhydrous alcohol cleaning for $2 \mathrm{~min}$. The geometrical parameters of precipitates were statically obtained by methods of the reference [18] and the standard variances of the aspect ratio, mean length and relative volume fraction of precipitate, yield strength and creep strain of the material corresponded to $1.68,6.76,3.77,3.51$, and 0.11 respectively.

\section{Results and Discussion.}

2.1. Creep Aging Behaviors. Creep strain-time curves of the alloy are drawn in Fig. 2. From the figure it can be clearly seen that each curve underwent typical primary and secondary creep stages. By comparison it is found that increasing stress level can shorten the duration of secondary creep but advance the advent of tertiary creep. Figure 3 illustrates the yield strength variation of material in CAF process. As the aging time prolonged, the yield strength increased first and then decreased gradually after reaching the peak value. Furthermore, compared with stress-free aging, creep aging not only enhances the yield strength but also shortens the time required to reach the maximum strength.

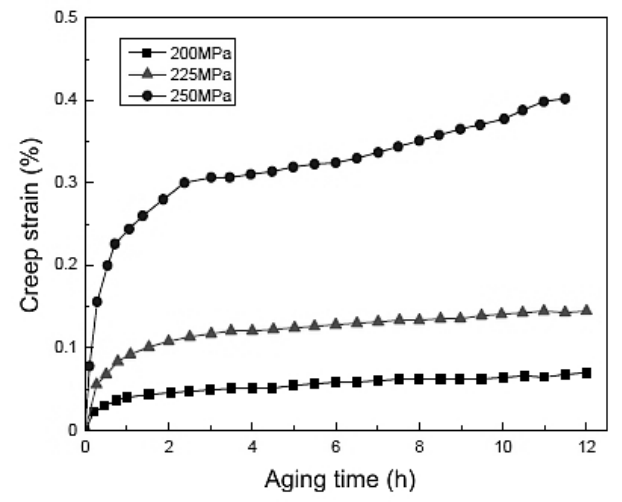

Fig. 2

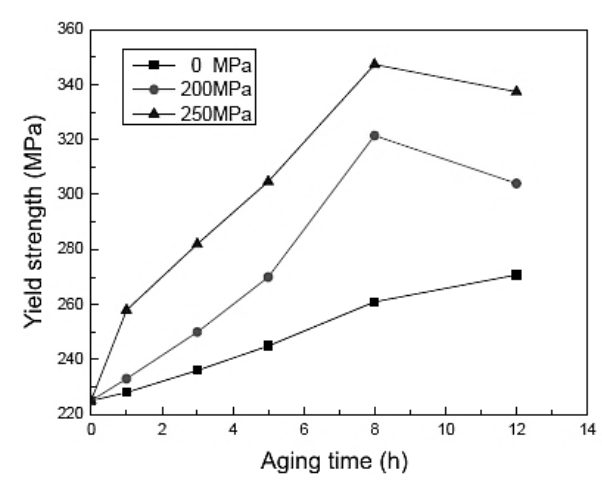

Fig. 3

Fig. 2. Creep strain-time curves of AA2124 specimens aged for $12 \mathrm{~h}$ at $185^{\circ} \mathrm{C}$ under different stresses.

Fig. 3. Variation of yield strength of AA212 specimens aged at $185^{\circ} \mathrm{C}$ under different stresses.

In $\mathrm{Al}-\mathrm{Cu}-\mathrm{Mg}$ alloys, the strengthening precipitate model can be simplified in Fig. 4a for plate shape and in Fig. 4b for rod shape [19]. For such precipitates, two characteristic parameters, i.e., average length $L$ and aspect ratio $q$ are chosen to describe the dimension evolution of precipitates in this paper. The aspect ratio equals to $L / h$, where $h$ is the mean thickness of plate-like precipitate or mean diameter of rod-like. Relevant research have found that dominate strengthening precipitates in creep aging of AA2124 are plate-like $S^{\prime}$ phases $\left(\mathrm{Al}_{2} \mathrm{CuMg}\right)$, as shown in Fig. $4 \mathrm{c}$, because the ratio between the content of $\mathrm{Cu}$ and $\mathrm{Mg}$ is less than $4[17,20]$. For simplicity, it is assumed here that only phases precipitate in CAF process. The general accepted precipitation sequence is SSS (supersaturated solid solution) $\rightarrow$ GP zone $\rightarrow \alpha-\mathrm{Al}+S^{\prime \prime} \rightarrow \alpha-\mathrm{Al}+S^{\prime} \rightarrow \alpha-\mathrm{Al}+S[21,22]$. The change trend of mean length of strengthening phase is depicted in Fig. 4d. The average length of 


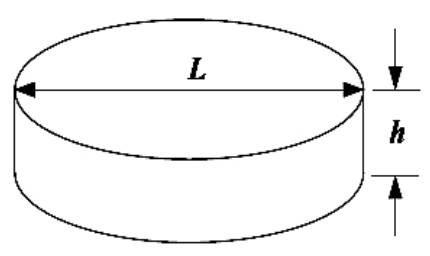

a

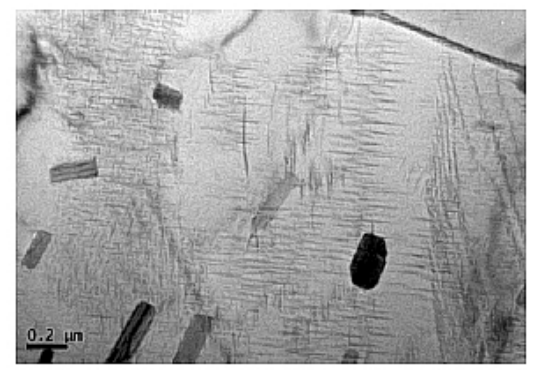

c

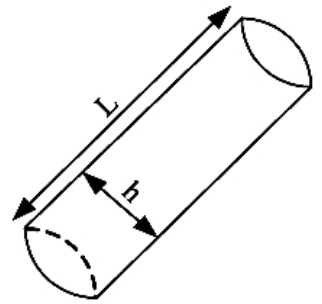

$\mathrm{b}$

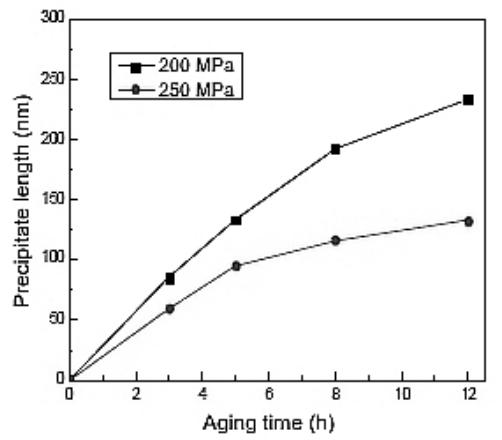

d

Fig. 4. A simplified mathematic model for plate-like precipitate (a), rod-like precipitate (b), TEM image of AA2 124 at $185^{\circ} \mathrm{C}$ for $8 \mathrm{~h}$ under $200 \mathrm{MPa}(\mathrm{c})$, average length of precipitate in specimen aged at $185^{\circ} \mathrm{C}$ under different stress levels: 200 and $250 \mathrm{MPa}(\mathrm{d})$.

precipitates increased monotonously with increasing aging time but the growth rate reduced gradually. This trend can be explained by the fact that the diffusion rate of solute atoms to form precipitates drops due to decreasing concentration of solute in the matrix. Besides, at high stress levels, the precipitate length was shorter. This is because more dislocations produced by the higher external load in aging process would cause acceleration in the heterogeneous nucleation of precipitates and increase precipitate density, which results in a low growth rate of precipitates to some extent.

2.2. Constitutive Model Establishment. Creep aging consists of creep deformation and aging heat treatment. In CAF process, the elastic strain is in part converted to permanent creep strain and this creep strain is responsible for retaining the final configuration of the part. Aging is a process that can increase the strength of a metal. Although some studies have been carried out the creep and aging as individual processes, when the two processes are combined in CAF, the interaction between them is highly sophisticated. On the one hand, massive dislocations are created due to external stress. These dislocations do affect precipitation process of the material, stress-induced orientation effect $[23,24]$ for instance, and eventually change material strength. On the other hand, the fine and dense precipitates formed in aging process improve the strength of the material [25]. The increase in strength of the alloy in turn impedes the creep deformation/rate. Consequently, material strength plays the role as a bridge between microscopic factors and macrocreep strain/rate.

Based on the understanding of creep aging and the knowledge of continuum mechanics and thermodynamics, a set of constitutive equations for $\mathrm{Al}-\mathrm{Cu}-\mathrm{Mg}$ alloys under isothermal aging treatment has been determined to describe the creep history, properties hardening and the evolution of microscopic factors. For ease of description, the equations are first listed as below: 


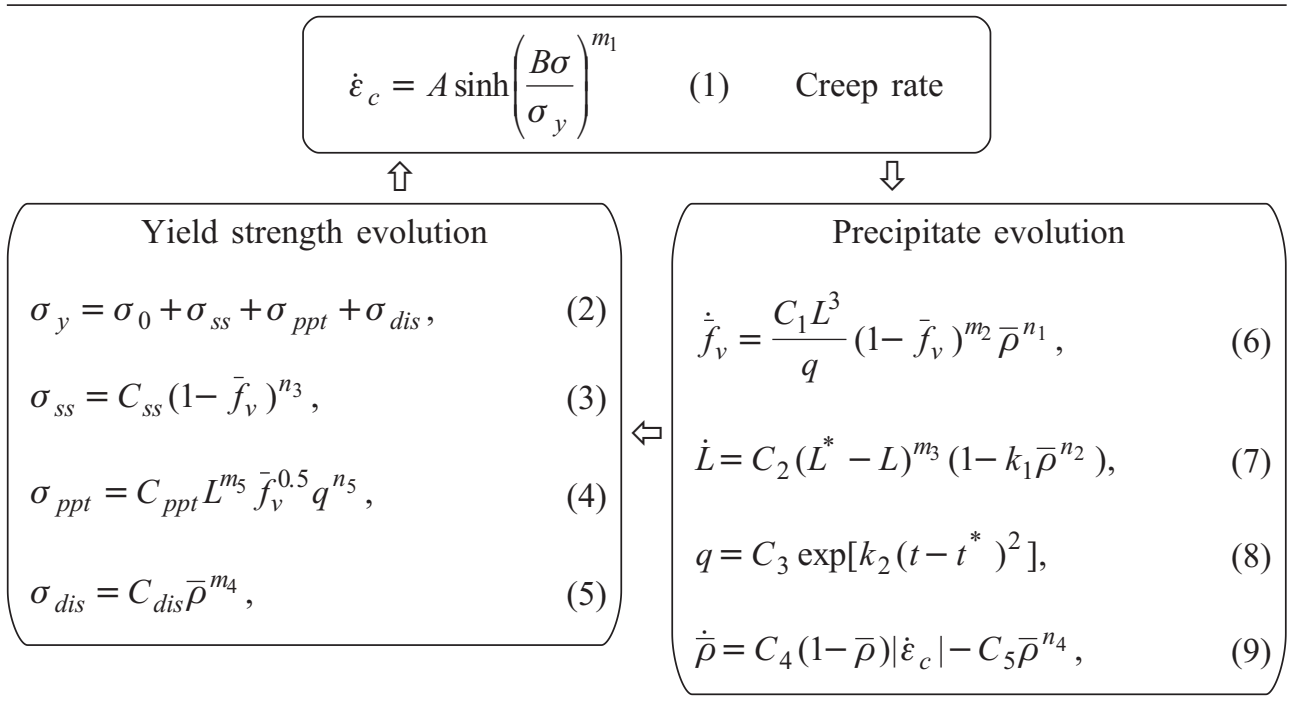

where $A, B, \sigma_{0}, k_{1}, k_{2}, C_{s s}, C_{p p t}, C_{d i s}, C_{1}, C_{2}, C_{3}, C_{4}, C_{5}, m_{1}, m_{2}, m_{3}, m_{4}, m_{5}$, $n_{1}, n_{2}, n_{3}, n_{4}, n_{5}, L^{*}$, and $t^{*}$ are material constants.

Equation (1) represents the evolution of creep strain under isothermal aging condition. Referring to Eq. (1), the change of creep strain is affected by the contradictory effects between externally applied stress $\sigma$ and material's yield strength $\sigma_{y}$. These effects are controlled by the exponent $\left(m_{1}\right)$ in sinh function. The yield strength varies with the microstructure evolution in the isothermal aging process (see Fig. 3). So the yield strength can be regarded as a junction between microstructure evolution and creep strain rate.

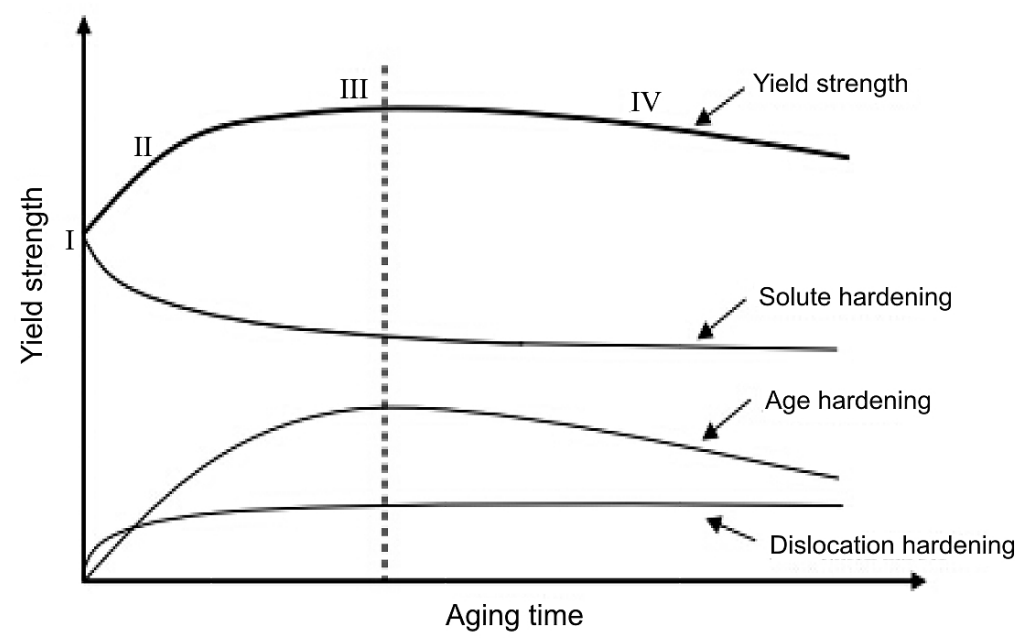

Fig. 5. Contributions of solid hardening, aging hardening, and dislocation hardening to yield strength.

Equations (2)-(5) depict the strengthening responses of material in creep aging. The contributions to the yield strength of the material in Eq. (2) are composed of the Al matrix strength $\left(\sigma_{0}\right)$, solution strengthening $\left(\sigma_{s s}\right)$, aging hardening $\left(\sigma_{p p t}\right)$ and dislocation strengthening $\left(\sigma_{d i s}\right)[26,27]$. A schematic for strengthening responses in CAF process is plotted in Fig. 5. Upon aging (stage I), the initial yield strength reveals the contributions from the intrinsic strength (Al matrix strength) and solute hardening because there is 
insufficient time for precipitate to nucleate in the water-quenched aluminum alloy. At the under-aged period (stage $I I$ ), transient second phases begin to form and dislocation density increases quickly leading to an increase in the yield strength. During this stage, the solute hardening effect decreases with decreasing solute concentration in the matrix. However, the decrease in solute hardening is less than offset by the increase owing to precipitate and dislocation hardening. So the overall strength increases as the precipitate grows. At stage III, yield strength reaches maximum value as there is no further decrease in solute hardening and no increase in aging hardening. With increasing aging time (stage $I V$ ), the yield strength begins to decrease because of the coarsening of precipitates.

For solid solution strength $\left(\sigma_{s S}\right)$, it can be calculated by the average concentration of solute in the matrix [28]: $\sigma_{s s}=\alpha \bar{C}_{t}^{n_{3}}$, where $\alpha$ and $n_{3}$ are material constants related to the discrepancy in crystal lattice between the solute atoms and matrix, and $\bar{C}_{t}$ is the current average concentration of solute. Shercliff and Ashby [28] found the correlation between solute concentration and relative volume fraction of precipitates, which can be expressed as $\bar{f}_{v}=\left(C_{l}-\bar{C}_{t}\right) /\left(C_{l}-C_{e}\right)$, where $C_{l}$ is the current solute concentration in the matrix and $C_{e}$ is the equilibrium solute concentration and approximates to zero theoretically, $\bar{f}_{v}$ denotes the relative volume fraction of precipitates that will be discussed later. Combining above two equations gives the expression of solid solution strength $\sigma_{s s}=C_{s s}\left(1-\bar{f}_{v}\right)^{n_{3}}$ [Eq. (3)].

Precipitation (aging) hardening embodies the contribution of precipitates to yield strength of the material. In this paper, the main strengthening precipitates ( $S^{\prime}$ phases) are always assumed to be unshearable. So these precipitates are bypassed by dislocations by the Orowan bowing process. Many strengthening models related to precipitates are made based on the above assumptions. Through analyzing the interaction force between precipitates and dislocations together with the mean distance between precipitates, Li et al. [16] deduced the expression of precipitation hardening as $\sigma_{p p t}=C_{p p t} L^{m_{5}} \bar{f}_{v}^{0.5}$. However, $\sigma_{p p t}$ only involves effects of mean length and relative volume fraction without consideration of the variation of precipitate thickness. Because of the non-coherent interface between precipitates and matrix on the peripheral plane of precipitate, the ability to receive atoms from the matrix to form second phases is strong. While for the plate planes of the precipitate, this ability is relatively weak due to the semi-coherent/coherent relationship. Although the growth rate along the length direction is larger than that of the thickness direction, the morphology of precipitate varies along length and thickness direction simultaneously. So the aspect ratio is employed in Eq. (4) to describe precipitation strengthening more accurately.

Dislocation strengthening is also called work hardening. It is essentially caused by increasing dislocation density in deformation process. The formula of dislocation strengthening is illustrated in Eq. (5), which is a function of normalized dislocation density $(\bar{\rho})$ defined by $[15]: \bar{\rho}=\left(\rho-\rho_{i}\right) / \rho_{m}$, where $\rho$ is the current dislocation density of Al matrix, $\rho_{i}$ is the dislocation density for the virgin material (the initial state), and $\rho_{m}$ is the maximum dislocation density that the material could have. When $\rho_{i}<<\rho_{m}$, the average dislocation density $\bar{\rho}$ varies from 0 to 1 . The evolution of average dislocation density is summarized in Eq. (9). The first term in Eq. (9) reveals the development of dislocation density due to creep deformation and the dynamic recovery. The second term gives the effect of static recovery in the dislocation density at higher temperature.

Equations (6)-(8) denote the evolution of microprecipitates. Three parameters including relative volume fraction $\bar{f}_{v}$, average length $L$, and aspect ratio $q$ are adopted to quantitatively characterize the precipitates. Relative volume fraction is defined by $\bar{f}_{v}=f_{v} / f_{v}^{*}$, where $f_{v}$ is the current volume fraction of precipitates and $f_{v}^{*}$ is maximum volume fraction. Based on the understanding of precipitation kinetic, the evolution of 
relative volume fraction is established in Eq. (6). The model not only includes the effects of precipitate growth, but also the effect of dislocation density.

Equation (7) refers to the development of the mean length of precipitates. The form of Eq. (7) consists of two parts. One part is that precipitates grow under a pure aging condition when dislocation density $\bar{\rho}$ approaches to zero. The other is that when external stress is applied, the dislocation density could have impacts on precipitates length, which is controlled by two parameters $k_{1}$ and $n_{2}$. Moreover, the parameter, $L^{*}$, the peak length of precipitate, is introduced to avoid the infinite increase of precipitate. This is consistent with the fact that precipitate in the matrix cannot grow continually because of the limitation of depletion of solute atoms from the aluminum matrix to precipitates. It is found that the value of aspect ratio $q$ of precipitates is not always the constant in aging process $[29,30]$. The change of aging processing conditions (aging temperature, time, material's constituent, etc.) has significant influences on aspect ratio and hence on yield strength. So the variation of aspect ratio during the isothermal aging is built in Eq. (8), i.e., $q=C_{3} \exp \left[k_{2}\left(t-t^{*}\right)^{2}\right]$, where $t^{*}$ is the time to obtain maximum aspect ratio, $t$ is the current aging time, and $C_{3}$ is material constituent dependence of constant.

2.3. Constitutive Model Verification. To verify the accuracy of the above constitutive equation set, the material constants for 2124 aluminum alloy are determined with the experimental results from the test. However, it is difficult to directly determine the material constants because there are too many constants and the number of constants is more than constitutive equations. It is better to use an optimization algorithm to get a set of approximate optimal solutions. In this study, an optimization algorithm called particle swarm optimization (PSO) was adopted to solve the material constants. Nevertheless, it is found that the fitness process often converges to local best but rarely to global best. Therefore, a step-by-step fitting process is used to calculate the material constants from microstructures to macroproperties aspect. First, the material constants related to aspect ratio, mean length and relative volume fraction were determined respectively. Second, the material constants related to macroperformances were determined that are yield strength and creep strain.

The derivation of material constants from the experimental data is evaluated by the fitness value when using PSO algorithm. The form of fitness value is listed as

$$
\text { Fit }=\frac{1}{n} \sum_{i=1}^{n}\left|\frac{x-x_{T}}{x_{T}}\right|,
$$

where $x$ and $x_{T}$ denote the computed and experimental data respectively, and $n$ is the number of data points.

The less the fitness value, the less the derivation of material constants from the experimental data. The values of all material constants are listed in Table 1 and the comparisons of experimental values and fitness curves are illustrated in Fig. 6 corresponding to (a) aspect ratio, (b) mean length, (c) relative volume fraction, (d) yield strength, and (e) creep strain with fitness values being respectively $6.80,4.65,8.98,1.73$, and $14.25 \%$. With regard to Fig. 6e, the discrepancy between the fitting curve and experimental data in the latter stage of creep tested under $250 \mathrm{MPa} / 185^{\circ} \mathrm{C}$ is relatively large. This is because that the specimen exhibits the tertiary creep at high temperature and high stress level, while the modeling process is not taken the nucleation and growth of microvoid that can bring about creep damage into account. Overall, the good agreement between experimental data and computed values confirms that the established constitutive models can well describe macrocreep behaviors, the variation of yield strength and precipitates evolution for $\mathrm{Al}-\mathrm{Cu}-\mathrm{Mg}$ alloys. 
Y. L. Yang, L. H. Zhan, and X. L. Xu

$\mathrm{T}$ a b 1 e 1

Material Constants within Constitutive Equation for 2124 Aluminum Alloy at $185^{\circ} \mathrm{C}$

\begin{tabular}{|c|c|c|c|c|c||}
\hline Constant & Value & Constant & Value & Constant & Value \\
\hline$A$ & $8.64 \cdot 10^{-6} \mathrm{~h}^{-1}$ & $C_{2}$ & 0.067 & $n_{1}$ & 1.09 \\
\hline$B$ & 1.64 & $C_{3}$ & 27.2 & $n_{2}$ & 1.21 \\
\hline$\sigma_{0}$ & $93 \mathrm{MPa}$ & $C_{4}$ & 179 & $n_{3}$ & 1.96 \\
\hline$k_{1}$ & 1.45 & $C_{5}$ & 0.01 & $n_{4}$ & 0.76 \\
\hline$k_{2}$ & $-0.03 \mathrm{~h}^{-2}$ & $m_{1}$ & 3.72 & $n_{5}$ & 0.32 \\
\hline$C_{s s}$ & $132 \mathrm{MPa}$ & $m_{2}$ & 1.95 & $L^{*}$ & $623 \mathrm{~nm}$ \\
\hline$C_{p p t}$ & $27.8 \mathrm{MPa}$ & $m_{3}$ & 0.95 & $t^{*}$ & $8 \mathrm{~h}$ \\
\hline$C_{d i s}$ & $129.3 \mathrm{MPa}$ & $m_{4}$ & 1.14 & & \\
\hline$C_{1}$ & $6.95 \cdot 10^{-5}$ & $m_{5}$ & 0.21 & & \\
\hline
\end{tabular}
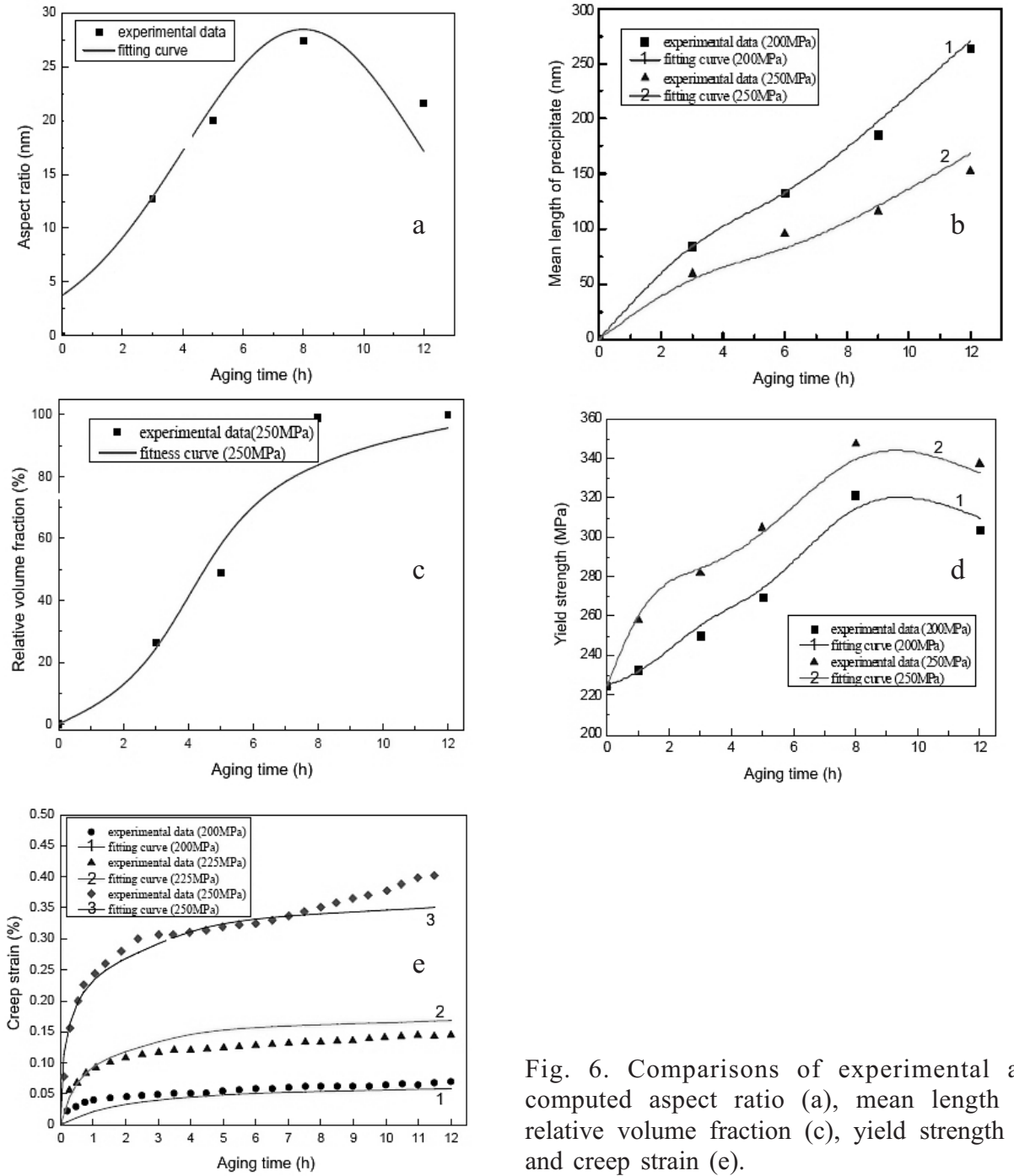

Fig. 6. Comparisons of experimental and computed aspect ratio (a), mean length (b), relative volume fraction (c), yield strength (d), and creep strain (e). 


\section{Conclusions}

1. With increasing aging time, the mean length of strengthening precipitates increases gradually, the aspect ratio varies in a low-to-high-to-low manner and precipitates volume fraction increases to the peak value and remains unchanged.

2. A unified mechanism-based creep constitutive equation set for $\mathrm{Al}-\mathrm{Cu}-\mathrm{Mg}$ alloys is established, which is a sinh function of externally applied stress and yield strength of materials. The material's yield strength links the microstructures with macroperformances. The models are not only suitable for plate-like precipitate but also suitable for rod-like one.

3. The good agreement between experimental data and computed values obtained by constitutive equation set confirms that the established constitutive models can well describe creep behaviors for $\mathrm{Al}-\mathrm{Cu}-\mathrm{Mg}$ alloy.

Acknowledgments. This research was supported by the National Basic Research Program of China (Grant No. 2014CB046602), the Key Program of National Natural Science Foundation of China (Grant No. 51235010), and Ph.D. Programs Foundation of Ministry of Education of China (Grant No. 20120162110003).

1. N. Zarei-Hanzaki A. and H. R. Abedi, "The flow behavior modeling of cast A356 aluminum alloy at elevated temperatures considering the effect of strain," Mater. Sci. Eng. A, 535, 252-257 (2012).

2. A. W. Zhu, J. Chen, and E. A. Starke, "Precipitation strengthening of stress-aged Al-xCu alloys," Acta Mater., 48, 2239-2246 (2000).

3. Y. Tian, L. Huang, H. J. Ma, and J. J. Li, "Establishment and comparison of four constitutive models of 5A02 aluminium alloy in high-velocity forming process," Mater. Des., 54, 587-597 (2014).

4. X. Tang, V. Prakash, J. J. Lewandowski, et al., "Inertial stabilization of buckling at high rates of loading and low test temperatures: Implications for dynamic crush resistance of aluminum-alloy-based sandwich plates with lattice core," Acta Mater., 55, 2829-2840 (2007).

5. X. Tang, D. Li , V. Prakash, and J. J. Lewandowski, "Effects of microstructure on high strain rate deformation and flow behaviour of Al-Mg-Si alloy (AA6061) under uniaxial compression and combined compression and shear loading," Mater. Sci. Technol., 27, 13-20 (2011).

6. H. N. G. Wadley, K. P. Dharmasena, M. R. O’Masta, and J. J. Wetzel, "Impact response of aluminum corrugated core sandwich panels," Int. J. Impact Eng., 62, 114-128 (2013).

7. J. G. Liu, S. Pattofatto, D. N. Fang, et al., "Impact strength enhancement of aluminum tetrahedral lattice truss core structures," Int. J. Impact Eng., 79, 3-13 (2015).

8. M. T. Ma, J. H. You, H. Z. Lu, and Z. W. Wang, "Research progress of aluminum alloy automotive sheet and application technology," Eng. Sci., 12, 4-20 (2010).

9. M. A. Hamstad, R. Bianchetti, and A. K. Mukherjee, "A correlation between acoustic emission and the fracture toughness of 2124-T851 aluminum," Eng. Fract. Mech., 9, 663-674 (1977).

10. Y. B. Liu, Z. Y. Liu, Y. T. Li, et al., "Enhanced fatigue crack propagation resistance of an Al-Cu-Mg alloy by artificial aging," Mater. Sci. Eng. A, 492, 333-336 (2008).

11. N. Kamp, N. Gao, M. J. Starink, and I. Sinclair, "Influence of grain structure and slip planarity on fatigue crack growth in low alloying artificially aged 2xxx aluminium alloys," Int. J. Fatigue, 29, 869-878 (2007). 
12. M. Sallah, J. Peddieson, Jr., and S. A. Foroudastan, "Mathematical model of autoclave age forming," J. Mater. Process. Technol., 28, 211-219 (1991).

13. Z. L. Kowalewski, D. R. Hayhurst, and B. F. Dyson, "Mechanisms-based creep constitutive equations for an aluminium alloy," J. Strain Anal. Eng. Des., 29, 309-316 (1994).

14. K. C. Ho, J. Lin, and T. A. Dean, "Constitutive modelling of primary creep for age forming an aluminium alloy," J. Mater. Process. Technol., 153, 122-127 (2004).

15. L. H. Zhan, J. G. Lin, T. A. Dean, and M. H. Huang, "Experimental studies and constitutive modelling of the hardening of aluminium alloy 7055 under creep age forming conditions," Int. J. Mech. Sci., 53, 595-605 (2011).

16. C. Li, M. Wan, X. Wu, and L. Huang, "Constitutive equations in creep of 7B04 aluminum alloys," Mater. Sci. Eng. A, 527, 3623-3629 (2010).

17. J. Zhang, Y. L. Deng, and X. M. Zhang, "Constitutive modeling for creep age forming of heat-treatable strengthening aluminum alloys containing plate or rod shaped precipitates," Mater. Sci. Eng. A, 563, 8-15 (2013).

18. X. Q. Zhao, M. J. Shi, J. H. Chen, et al., "A facile electron microscopy method for measuring precipitate volume fractions in AlCuMg alloys," Mater. Charact., 69, 31-36 (2012).

19. G. Liu, X. D. Ding, J. Sun, and K. H. Chen, "A model for age strengthening of platelike-precipitate-containing Al alloys," Chin. J. Nonferrous Met., 11, 337-347 (2001).

20. Y. G. Li, Experimental Study and Constitutive Modeling on Creep Aging for 2124 Aluminum Alloy, Central South University, Changsha (2012).

21. S. M. Kumaran, "Evaluation of precipitation reaction in $2024 \mathrm{Al}-\mathrm{Cu}$ alloy through ultrasonic parameters," Mater. Sci. Eng. A, 528, 4152-4158 (2011).

22. C. Badini, F. Marino, and E. Verne, "Calorimetric study on precipitation path in 2024 alloy and its SiC composite," Mater. Sci. Eng. A, 191, 185-191 (1995).

23. A. W. Zhu and E. A. Starke, "Stress aging of Al-Cu alloys: computer modeling," Acta Mater., 49, 3063-3069 (2001).

24. D. Q. Chen, Z. Q. Zhen, S. C. Li, et al., "Effect of external stress on the growth of precipitates in Al-Cu and Al-Cu-Mg-Ag alloys," Acta Metall., 40, 799-804 (2004).

25. A. W. Zhu and E. A. Starke, "Strengthening effect of unshearable particles of finite size: A computer experimental study," Acta Mater., 47, 3263-3269 (1999).

26. F. Barlat, M. V. Glazov, J. C. Brem, and D. J. Lege, "A simple model for dislocation behavior, strain and strain rate hardening evolution in deforming aluminum alloys," Int. J. Plast., 18, 919-939 (2002).

27. J. D. Teixeira, D. G. Cram, L. Bourgeois, et al., "On the strengthening response of aluminum alloys containing shear-resistant plate-shaped precipitates," Acta Mater., 56, 6109-6122 (2008).

28. H. R. Shercliff and M. F. Ashby, "A process model for age hardening of aluminium alloys - I. The model," Acta Metall. Mater., 38, 1789-1802 (1990).

29. G. Liu, J. Sun, C. W. Nan, and K. H. Chen, "Experiment and multiscale modeling of the coupled influence of constituents and precipitates on the ductile fracture of heat-treatable aluminum alloys," Acta Mater., 53, 3459-3468 (2005).

30. G. Liu, G. J. Zhang, X. D. Ding, et al., "Modeling the strengthening response to aging process of heat-treatable aluminum alloys containing plate/disc- or rod/needle-shaped precipitates," Mater. Sci. Eng. A, 344, 113-124 (2003). 